\title{
Semblanza del Doctor José Torres Ortega
}

\author{
Tribute to Dr Jose Torres Ortega
}

El Dr. José Torres Ortega nació un 18 de septiembre en Santiago. Estudió preparatorias en la Escuela Pública $\mathrm{N}^{\mathrm{o}} 14$ y humanidades en el Instituto Nacional. Ingresó a la Escuela de Medicina de la Universidad de Chile en 1946. Obtuvo el Título de Médico Cirujano en 1952 e ingresó al Servicio de Cirugía del Profesor Italo Alessandrini en el Hospital del Salvador. Este Servicio fue trasladado al recién inaugurado Hospital San Juan de Dios, en 1954, y fue asignado al equipo del Dr. Gustavo Barrera, quien al igual que el Profesor Alessandrini, tenía un especial interés por la cirugía del área cérvico-facial.

En aquella época los cirujanos atendían todo tipo de enfermedades quirúrgicas, pero la tendencia hacia la especialización se fue haciendo evidente; esto condujo a una creciente derivación de pacientes hacia aquellos equipos que demostraron especial interés por determinadas afecciones.

El equipo del Dr. Barrera operaba frecuentemente, pacientes con enfermedades del área cervicofacial, lo que condujo a que los miembros de este equipo obtuvieran experiencia en la cirugía de esta región.

El Dr. Barrera a muy temprana edad, sufrió una lesión cerebral y falleció en forma trágica varios meses después. El grupo que él había formado, continuó operando los pacientes de esta especialidad y el Dr. Torres asumió la iniciativa y el liderazgo del grupo.

El Dr. Torres efectuó numerosas disecciones de la parótida y nervio facial, y esto, sumado a su experiencia quirúrgica en esta área dió origen a una investigación que demostró que la glándula parótida no estaba dividida en dos lóbulos por un tabique por el que discurría el nervio facial, como se había postulado por algunos autores, sino que este nervio y sus divisiones penetraban el parénquima de la glándula, para distribuirse en la musculatura de la mímica facial. Este novedoso trabajo titulado Anatomía y Cirugía de la Parótida y Nervio Facial, permitió el ingreso del Dr. Torres a la Sociedad de Cirujanos de Chile el año 1958.

El desarrollo del equipo de Cabeza y Cuello se incrementó gracias al espíritu inquieto y entusiasta del Dr. Torres. Desde temprano se dedicó a estudiar las técnicas quirúrgicas pertinentes, modificando algunas y perfeccionando otras.
Inició el entrenamiento de cirujanos jóvenes interesados en esta cirugía, labor que ha mantenido desde esa época hasta hace algunos meses. Un significativo número de cirujanos lo reconoce como su principal formador y están dispersos en distintos puntos del país y unos pocos en el extranjero.

Es prácticamente imposible enumerar los logros alcanzados por el Dr. Torres en su extensa y exitosa carrera, como cirujano, académico e investigador, sin interrupción, salvo en períodos de ausencia del país para perfeccionamiento en el extranjero.

Haré un breve resumen, mencionando parte de sus múltiples acciones y logros.

Inició su actividad, como ayudante de Anatomía en la Cátedra del Profesor Gustavo Jirón, donde permaneció por 10 años. Contemporáneamente ingresó como ayudante de Cirugía del Profesor Italo Alessandrini en el Hospital San Juan de Dios. Pronto ascendió a Instructor de Cirugía. Fue nombrado Profesor encargado de curso desde 1961 a 1971; luego obtuvo el grado de Profesor Asociado en 1971, y en 1983 el de Profesor Titular de Cirugía de la Facultad de Medicina de la Universidad de Chile. Asumió como Director del Departamento de Cirugía del Hospital San Juan de Dios en 1991 y permaneció en este cargo hasta 1995. Posteriormente, se desempeñó como Subdirector de ese Departamento desde 1966 hasta el año 2000. Fue nombrado Jefe del Programa de Especialistas en Cirugía de Cabeza y Cuello en el Departamento de Cirugía del área Occidente. Desde sus primeros años como instructor hasta su jubilación y ulterior recontratación, ha continuado ejerciendo docencia, asistencia e investigación. Todas las generaciones de estudiantes de Medicina de cuarto año que le conocieron y compartieron con él en el Proceso de Enseñanza-Aprendizaje, le han demostrado por escrito su trato respetuoso, cariñoso, compañerismo y eficiencia, y esto los llevó a considerarlo como un destacado y ejemplar docente.

Se destacó en forma eficiente en la creación, organización, perfeccionamiento y participación en varios comités relacionados con el estudio, diagnóstico y toma de decisiones en pacientes de la especialidad. Destacan en su currículum, una constante participación en Congresos nacionales e internacionales, Dirección de Cursos de Postgrado, interacción con Centros del Área Norte y Provincia; participación 
activa en cursos de formación y comités de certificación de especialistas y cirujanos generales.

Fue miembro de diversas Comisiones de Estudio en el Ministerio de Salud y en la Facultad de Medicina de la Universidad de Chile. Tiene activa participación en Comités de Selección y Exámenes de Acreditación de la Especialidad en CONACEM.

$\mathrm{Su}$ actividad en la organización, desarrollo y control de los programas de formación en el pre y post grado ha sido significativa.

Fue miembro fundador de la Sociedad de Cirugía de Cabeza y Cuello de la que llegó a ser su Presidente. Es miembro de la Sociedad de Cirujanos de Chile desde 1958 y fue nombrado Miembro Emérito en el año 2000. Fue miembro de la Sociedad Médica de Santiago y de la Sociedad Chilena de Endocrinología y Metabolismo, así como, de la Sociedad Argentina de Patología de Cabeza y Cuello, de la Sociedad de Cancerología de Río Grande do Sul y de la Society of Head and Neck Surgeons of New York.

Fue Fellow de la Clínica Lahey de Boston y visitante de la Clínica Joslin de esa ciudad; Visiting Surgeon del Memorial Sloan-Kettering Cancer Center de New York y del Massachussets General Hospital de Boston.

Ha publicado ochenta trabajos la mayoría concerniente a temas de la especialidad, en la Revista Chilena de Cirugía y en el Boletín del Hospital San Juan de Dios. Dos trabajos, uno relacionado con la supervivencia en el cáncer diferenciado del tiroides, fueron premiados por la Sociedad de Cirujanos y publicados, en la Revista Cáncer uno y el otro, relacionado con los factores pronosticadores del Cáncer Diferenciado del Tiroides (segundo autor), en la Revista Chilena de Cirugía en diciembre de 2011.

No insistiré en enumerar sus múltiples actividades académicas y sus logros quirúrgicos, porque pienso que es más importante dar a conocer algunas facetas de su condición de formador que lo ha hecho merecedor del Título de Maestro de la Cirugía Chilena. Como lo expresé previamente, el Dr. Torres se inició muy temprano en la Docencia. En el ambiente de su equipo, exigió siempre, seriedad compromiso y disciplina. Controló a sus discípulos en forma muy estricta en el conocimiento de los pacientes, su enfermedad y posibilidades terapéuticas. Exigía una descripción de la anatomía, relaciones y función de las regiones u órganos que debíamos intervenir. Nos exigía explicar al paciente la naturaleza de su enfermedad, las posibilidades terapéuticas, los beneficios que se obtendrían y los riesgos de posibles complicaciones.

En el pabellón se mantenía silencioso, observando atentamente nuestra acción y de cuando en cuando nos advertía verbalmente o bien con un golpe de pinza en los nudillos, cuando estábamos a punto de efectuar una maniobra no establecida previamente. La disección debía ser cortante y con bisturí y tijeras; debíamos usar diatermia en forma excepcional, nunca coagular en exceso, debíamos pinzar sólo el vaso sangrante y no todo su entorno, evitar la tensión de las suturas y otros detalles de su técnica minuciosa.

Nos introdujo en la práctica de la magnificación para reconocer con exactitud los detalles anatómicos. Con el tiempo nos enseñó y aprendimos esos pequeños detalles técnicos y variaciones personales que sólo se adquieren con una larga e inteligente experiencia.

Siempre nos ha llamado la atención su destreza y seguridad en el reconocimiento de los planos anatómicos de regiones alteradas por procesos tumorales o sépticos. Tiene la habilidad de orientarse en zonas en que nada parece estar en su lugar original. Es destacable su delicadeza y finura en la disección, que aún mantiene, logrando un mínimo daño tisular que acelera el proceso de recuperación del paciente.

Su técnica de enseñanza ha consistido en ayudar al cirujano de menor experiencia facilitando su acción con un apoyo eficiente y asistirlos en los momentos de dificultad o dudas, sin comentarios negativos o mordaces. Si tiene que criticar una acción mal ejecutada, no lo hace durante la operación, prefiere reunirse en forma privada con el cirujano, explicarle en forma asertiva cual fue el error o los errores, sus causas e indicarle la forma de corregirlos, siempre manteniendo una actitud positiva que no deja resquemores. Mantiene con firmeza el principio: "que en las operaciones no hay detalles pequeños", y que toda acción quirúrgica mal ejecutada suele generar consecuencias.

Una cualidad que hay que destacar fuertemente es el cariño y respeto que manifiesta por sus pacientes, especialmente evidente con aquellas personas más humildes y desvalidas. Muchas veces se ocupó personalmente de ubicar un examen, una ficha extraviada y en ocasiones acompañar al paciente a una interconsulta.

El Dr. Torres durante la fase inicial de su carrera incursionó en otras áreas del quehacer quirúrgico, siempre con su habitual compromiso y dedicación. No obstante, su principal y más importante línea de acción la desarrolló en el área de la cirugía de cabeza y cuello.

Creo importante relatar algunas situaciones propias de su perfil de carácter tan especial. Durante la Segunda Guerra Mundial él era adolescente y cursaba los últimos años de humanidades. Se presentó junto con un compañero en el Consulado de la Embajada de Inglaterra para ser enrolados como voluntarios y servir como pilotos de guerra en la 
Real Fuerza Aérea. Su mayor ambición era pilotear un Spitfire y derribar un Messerschmitt 109. El funcionario del consulado, les agradeció el interés de su intento por cooperar con Inglaterra y les aclaró que debido a su edad, esto aún no era posible. Les regaló insignias de la RAF y algunas revistas referentes a la guerra. Esta anécdota nos ayuda a comprender en parte su espíritu de decisión y lucha que nunca le ha abandonado.

José Torres es un hombre de ceño adusto, facies seria, pragmático y poco proclive a aceptar lo que no comprueba personalmente. En una lista de sus características podríamos enumerar que es un hombre leal, crítico, práctico, muy detallista, analítico y metódico, muy reservado y normalmente silencioso. Gusta de la soledad y practica meditación. Trabaja sin pensar en el descanso. Es moderado en sus manifestaciones de afecto, aún cuando, genera sentimientos positivos y emociones genuinas las que se expresan sin exuberancia. Es un hábil artesano, especialmente de cosas pequeñas. Predominan sus manifestaciones artísticas, es muy buen dibujante y pintor; activo lector, especialmente de historia y es un experto en el conocimiento del desarrollo de la segunda guerra mundial.

Especialmente iterativo en el control de su gru- po, tiende a enfatizar sobre la base de las certezas que ha obtenido por su pericia técnica y probada experiencias.

He trabajado y compartido con el Dr. Torres, el querido Don Pepe, como se le llama, durante varios decenios y creo haber llegado a conocerlo muy bien.

He pensado con Soledad Torres, que nos podemos considerar hermanos; ella es su hija biológica y yo su hijo quirúrgico.

Pepe Torres me enseñó su Cirugía al viejo estilo Hipocrático, lado a lado, sin guardar secretos, siempre con su cariño, poco expresivo pero claramente reconocible para aquellos que lo queremos, bien.

En esta ocasión a pesar de estar muy lejos en persona pero muy presente en espíritu, quiero agradecerle frente a todos ustedes, sus amigos, colegas y compañeros de toda una vida, por todo lo que entregó con su ejemplo como Docente, Cirujano y como hombre.

Felicitarlo con todo mi cariño y admiración por su merecido nombramiento como Maestro de la Cirugía Chilena.

Dr. Roberto Volpato D. Hospital del Trabajador Santiago, Chile 